\title{
Collegiate Athletic Trainers' Perceived and Actual Knowledge of Therapeutic Ultrasound Concepts
}

Kristen Couper Schellhase, EdD, LAT, ATC, CSCS, Jennifer L. Plant, MSEd, LAT, ATC, CSCS, and Carey E. Rothschild, PT, DPT, OCS, CSCS • University of Central Florida

Context: Therapeutic ultrasound is a widely used modality, however, little is known about the knowledge level of athletic trainers regarding therapeutic ultrasound. Objective: To examine athletic trainers' perceived and actual knowledge of therapeutic ultrasound concepts. Design: Cross-sectional. Setting: Web-based. Patients or Other Participants: Randomly selected collegiate athletic trainers (35.55 \pm 8.86 years). Intervention: The questionnaire included: Likert scale questions regarding perceived knowledge of the educational competencies related to therapeutic ultrasound; actual knowledge questions regarding theory/textbook validated knowledge; frequency of use questions; and demographics. Main Outcome Measures: Correlations. Results: Athletic trainers in collegiate settings reported fairly high confidence in their knowledge of the application-related therapeutic ultrasound competencies. Athletic trainers reported less confidence in their knowledge of the theory-related competencies. The actual knowledge mean score was $15.50 \pm 2.88$ out of 22 possible points. The 13 questions that were answered correctly by less than $75 \%$ of the participants related to insufficient parameters, safety concerns, and theory/book knowledge. Weak to moderate positive relationships were found between actual knowledge scores and perceived knowledge scores, age group, and number of therapeutic modalities courses taken. Weak to moderate positive relationships were found between perceived knowledge scores and both age group and number of courses taken. Conclusions: Athletic trainers were more confident with application-based questions than they were with theory-based questions. Though overall confidence in their knowledge of therapeutic ultrasound concepts was high, actual knowledge scores were relatively poor. Actual knowledge scores were higher in older age groups and in those who had taken more therapeutic modalities courses. The use of inadequate intensities and inadequate treatment durations, as outlined by Draper in 1998, were still seen. While a self-assessment tool may be helpful for some, this study suggests that more research is needed regarding whether athletic trainers have an accurate understanding of their need for continuing education in this area.

U Itrasound is a popular therapeutic modality that has been used to treat orthopedic conditions since the 1950s. ${ }^{1-4}$ The clinical application of therapeutic ultrasound has evolved over the past several decades, from being used exclusively as a thermal modality to being employed for its nonthermal effects, particularly in tissue repair and wound healing. ${ }^{5,6}$ Correct application of therapeutic ultrasound can aid in the treatment of musculoskeletal injuries, whereas incorrect application may reduce the desired physiological effects or even cause harm to the patient. ${ }^{7}$ Despite its widespread use, little is known about the perceived and actual knowledge level of athletic trainers regarding therapeutic ultrasound. Armijo-Olivo et al. investigated the beliefs and sources of knowledge of therapeutic ultrasound of Canadian physical therapists, but no such study has 


\section{KEY POINTS}

Collegiate athletic trainers were confident

in their knowledge regarding therapeutic ultrasound concepts.

Higher confidence was reported for application questions versus theory questions.

Though perceived confidence was high, actual knowledge scores were fairly low.

Respondents in an older age group and respondents who had taken more therapeutic modalities courses tended to have higher actual knowledge scores.

The use of inadequate intensities and inadequate treatment durations were seen. been performed to date regarding athletic trainers. ${ }^{5}$

Athletic trainers have met a minimum standard of therapeutic modalities knowledge by graduating with a degree in athletic training and passing a certification examination; however, the retention of knowledge by athletic trainers once they become certified is unclear. A literature search uncovered no studies that analyzed athletic trainers' retention of knowledge postcertification. However, a review of literature in other health care professions found that knowledge and skill related to emergency care begins to decline within six months to one year after training. ${ }^{8}$ Furthermore, early athletic training curricula relied less on a set coursework and more on a demanding clinical component for the attainment of knowledge and skills. ${ }^{9}$ While the fifth edition of Athletic Training Educational Competencies ${ }^{10}$ contains nine competencies/proficiencies that directly apply to the theory, application, and intended outcomes of therapeutic ultrasound, these requirements have not always been in place, and many athletic trainers graduated and passed their certification examination before the current understanding of modern therapeutic ultrasound principles. While the Board of Certification (BOC) requires athletic trainers to participate in continuing education, it does not currently require athletic trainers to provide evidence that they have current knowledge in any specific subject other than emergency cardiac care. ${ }^{11}$ Therefore, it is important to understand the level of knowledge regarding therapeutic ultrasound concepts among athletic trainers.

\section{Procedures and Findings}

We recruited participants by requesting the e-mail contact information for a random sample of 1,000 athletic trainers through the National Athletic Trainers'
Association (NATA) research survey service. Selected individuals were required to be employed athletic trainers (any setting), certified, not retired, and from the United States. The research proposal was evaluated and approved as exempt from regulation by the researchers' university institutional review board (IRB). Participants were informed of the study's purpose and their completion of the questionnaire served as their consent to participate.

An electronic mail message was sent that invited participants to complete a questionnaire via a hyperlink to SurveyMonkey/Audience (http://www.survey monkey.com/mp/audience/). The recruitment message contained information about the researchers, purpose of the study, selection process, nature of the questionnaire, and IRB information. We sent two follow-up emails, one month and two months after the original request.

The perceived knowledge items included all of the therapeutic intervention (TI) competencies related to therapeutic ultrasound that were contained in the fifth edition of Athletic Training Educational Competencies. ${ }^{10}$ The competencies are required elements of any current athletic training professional degree program curriculum, and the intent was to determine how confident currently practicing athletic trainers felt with those same competencies. Participants were given the stem of "I feel confident in my knowledge and understanding of, and am able to..." and then asked to choose from "strongly agree" (4), "agree" (3), “disagree" (2), "strongly disagree" (1), or "cannot determine" (2.5).

The actual knowledge section was created using the results from a review of literature that revealed common misconceptions regarding therapeutic ultrasound. ${ }^{7}$ This section was designed by an instructor who had been teaching the therapeutic modalities course within a professional athletic training program for 10 years. Questions were designed to mimic an examination given to students in an athletic training program. Twenty-four preceptors and faculty at the researchers' institution were asked to complete the questionnaire and their feedback was used to increase the clarity of questions and response choices. Once this was complete, all test questions and answers were validated by using three therapeutic modalities textbooks. ${ }^{12-14}$ If the question phrasing and answer could not be validated through all three textbooks, it was not included in the final questionnaire. The final questionnaire consisted of the following: nine Likert scale items that evaluated participants' perceived knowledge; a knowledge test 
containing 12 multiple choice questions, eight true or false questions, and three clinical decision questions; six frequency of use questions; and nine demographic questions.

The results were analyzed using SPSS version 21 (IBM, Armonk, NY). Of the 1,000 athletic trainers contacted for participation, $147(14.7 \%)$ athletic trainers responded, and 119 participants completed all four sections $(n=119,11.9 \%)$. Of the 119 , 111 were from the college setting. The very small number of participants who worked in other settings meant that the results could not be generalized to those settings. In addition, two respondents' data were excluded due to outlier data. Therefore, the data analysis only included those $109(10.9 \%)$ participants in collegiate settings, and results can only be generalized to those settings.

There were 61 (56\%) participants who reported working as an athletic trainer in a college/clinical setting, $41(37.6 \%)$ in a college/academic setting, and 7 (6.4\%) who reported working in both roles (college/ split appointment). The mean participant age was $35.57 \pm 8.92$ years. Most respondents reported taking either one or two courses $(n=91,83.5 \%)$ in therapeutic modalities. Participant demographic information and descriptive information for setting, age, number of therapeutic modalities courses taken, and degrees earned are presented in Table 1. Most participants

\begin{tabular}{|lc|}
\hline \multicolumn{2}{|c|}{ TABLE 1. PARTICIPANT } \\
DEMOGRAPHICS \\
Variable & $\begin{array}{c}\text { Frequency } \\
\text { (\%) }\end{array}$ \\
Current setting $(n=109)$ & \\
College/university (clinical) & $61(56.0)$ \\
College/university (academic) & $41(37.6)$ \\
College/split appointment & $7(6.4)$ \\
Age $(n=108)$ & \\
$20-29$ years & $32(29.4)$ \\
$30-39$ years & $48(44.0)$ \\
$40-49$ years & $19(17.4)$ \\
$50-59$ years & $9(8.3)$ \\
Modalities courses completed $(n=108)$ & \\
None & $4(3.7)$ \\
\hline 1 course & $58(53.2)$ \\
2 courses & $33(30.3)$ \\
\hline 3 courses & $11(10.1)$ \\
4 courses & $2(1.8)$ \\
\hline
\end{tabular}

\begin{tabular}{|c|c|}
\hline Variable & $\begin{array}{l}\text { Frequency } \\
(\%)\end{array}$ \\
\hline \multicolumn{2}{|l|}{ Undergraduate degree* } \\
\hline Physical therapy & 1 \\
\hline Biomechanics/kinesiology & 1 \\
\hline Education & 2 \\
\hline Exercise physiology/science & 8 \\
\hline Health & 4 \\
\hline Physical education & 9 \\
\hline $\begin{array}{l}\text { Sports medicine/athletic training } \\
\text { (internship) }\end{array}$ & 22 \\
\hline Athletic training (accredited) & 69 \\
\hline Biology & 2 \\
\hline Other & 2 \\
\hline \multicolumn{2}{|l|}{ Master's degree* } \\
\hline Biomechanics/kinesiology & 8 \\
\hline Education & 8 \\
\hline Exercise physiology/science & 12 \\
\hline Health and human performance & 4 \\
\hline Health education & 9 \\
\hline Physical education & 5 \\
\hline Physical therapy & 2 \\
\hline Sports administration & 12 \\
\hline $\begin{array}{l}\text { Sports medicine/athletic training } \\
\text { (postprofessional) }\end{array}$ & 40 \\
\hline Athletic training (entry-level master's) & 9 \\
\hline Health care administration & 1 \\
\hline Public health & 1 \\
\hline Sport law & 1 \\
\hline No master's degree & 5 \\
\hline \multicolumn{2}{|l|}{ Doctoral degree $(n=40)$} \\
\hline Biomechanics & 2 \\
\hline Curriculum and instruction & 2 \\
\hline Education leadership & 5 \\
\hline Exercise physiology/science & 4 \\
\hline Health and human performance & 1 \\
\hline Health education & 1 \\
\hline Higher education & 3 \\
\hline Higher education administration & 2 \\
\hline Physical therapy & 4 \\
\hline Sports medicine/athletic training & 10 \\
\hline Kinesiology & 2 \\
\hline Nutrition & 1 \\
\hline Physical medicine and rehabilitation & 1 \\
\hline Prevention science & 1 \\
\hline Other & 1 \\
\hline
\end{tabular}

*The number of bachelor's and master's degrees exceeds 109 because participants were allowed to choose more than one degree earned. 
reported weekly use of therapeutic ultrasound on thermal $(n=89,81.5 \%)$ and nonthermal intensities $(n=$ $71,65.2 \%)$, and in combination with electrical stimulation ( $n=66,60.6 \%$ ). Most participants reported that they "never" use the bladder/gel pad method $(n=82$, $75.2 \%)$, the underwater/submersion method $(n=76$, $69.7 \%$ ), and/or phonophoresis ( $n=86,78.9 \%$ ). Participant responses for the frequency of use questions are presented in Table 2.

The overall Chronbach $\alpha$ for the perceived knowledge section was .852, indicating a good level of internal consistency. Correlation coefficients were substantial at .585. Principal axis factoring (two fixed factors) and promax rotation revealed four questions loading under factor one, three questions loading under factor two, and two factors that loaded under both factors. The four questions that loaded under factor one were identified by the researchers as "application" questions. The three questions that loaded under factor two were identified by the researchers as "theory/book knowledge" questions. The factors and loadings are outlined in Table 3.

The mean score on the perceived knowledge section was $30.13 \pm 4.0$ out of 36 possible points. Participants reported fairly high confidence in their knowledge and understanding of the therapeutic ultrasound competencies that were identified by the researchers as "application" questions; $60 \%$ or more of respondents replied that they "strongly agree" that they are confident with those competencies. Participants reported less confidence in their knowledge and understanding of the therapeutic ultrasound competencies that were identified by the researchers as "theory" questions; while most responded that they at least "agree", $46 \%$ or less reported that they "strongly agree" that they are confident with those competencies. The distribution of responses for the perceived knowledge competency content questions are reported in Table 4.

One question was excluded from the actual knowledge analysis due to a typo on the questionnaire. The mean score on the actual knowledge section was $15.50 \pm 2.88$ out of 22 possible points $(70.45 \% \pm$ $13.09 \%$ out of $100 \%)$. The 13 questions that were answered correctly by less than $75 \%$ of the participants were categorized by the researchers: three were considered to regard "insufficient parameters", three indicated "safety concerns", and seven were "theory/ book knowledge". Those questions that were correctly answered by less than $75 \%$ of the participants are identified in Table 5.
The Shapiro-Wilk test of normality (.097), and other indices including skewness (-.114) and kurtosis (-.514) and examination of histogram and $\mathrm{Q}-\mathrm{Q}$ plots, indicated that the actual score has a normal distribution. Indicators of normality for the perceived knowledge score indicated concern regarding a nonnormal distribution. The Shapiro-Wilk test of normality was significant ( $p \leq$ $.001)$ and the distribution was highly negatively skewed $(-.086)$. Kurtosis $(-.988)$ and examination of histogram and Q-Q plots also pointed toward a nonnormal distribution of perceived knowledge scores.

A Spearman correlation was used to determine the relationships between a respondent's actual knowledge scores and their perceived knowledge scores, their age group, and the number of therapeutic modalities courses they had taken. A Bonferroni correction was made using .05/6 comparisons made. The corrected alpha level became .00833 . Significant weak to moderate positive relationships were found between actual knowledge scores and perceived knowledge scores $\left(r_{s}\right.$ $[109]=.319, p=.001)$; age group $\left(r_{s}[109]=.265, p\right.$ $=.005)$; and number of therapeutic modalities courses taken $\left(r_{\mathrm{s}}[109]=.351, p=.001\right)$. Respondents who had higher perceived knowledge scores, respondents in an older age group, and respondents who had taken more therapeutic modalities courses tended to have higher actual knowledge scores. In addition, significant weak to moderate positive correlations were found between perceived knowledge scores and age group $\left(r_{s}[109]=.349, p \leq .001\right)$, as well as perceived knowledge scores and the number of therapeutic modalities courses taken $\left(r_{s}[109]=.326, p=.001\right)$. Those respondents who were in older age groups and those who had taken more therapeutic modalities courses tended to have higher perceived knowledge scores.

\section{Discussion}

\section{Perceived and Actual Knowledge}

In 2001, Cuppett ${ }^{15}$ examined the self-perceived continuing education needs of athletic trainers in a variety of settings. Athletic trainers in that study reported substantial need in the area of "rehabilitation and reconditioning", the domain in the third edition Role Delineation Study (RDS) that listed the skills related to therapeutic modalities. The two tasks that included therapeutic modalities skills were rated a 4.18 and 4.16 out of 5 , with 5 indicating a "substantial need" for continuing education in the task. ${ }^{15}$ This indicates 


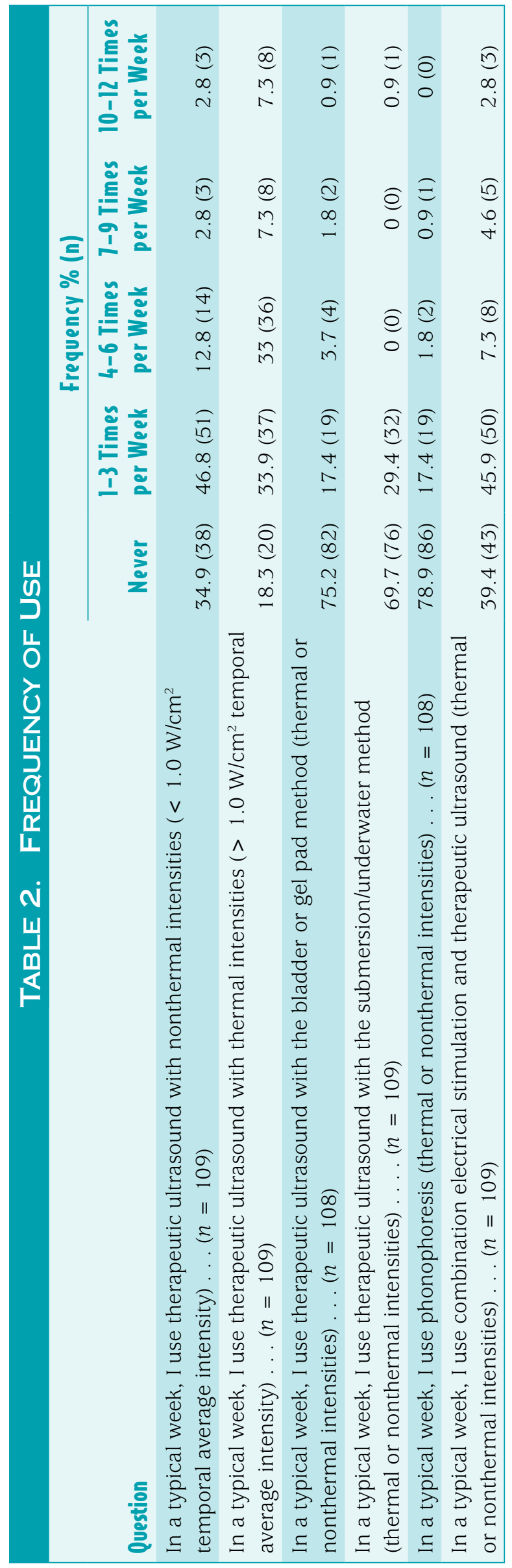




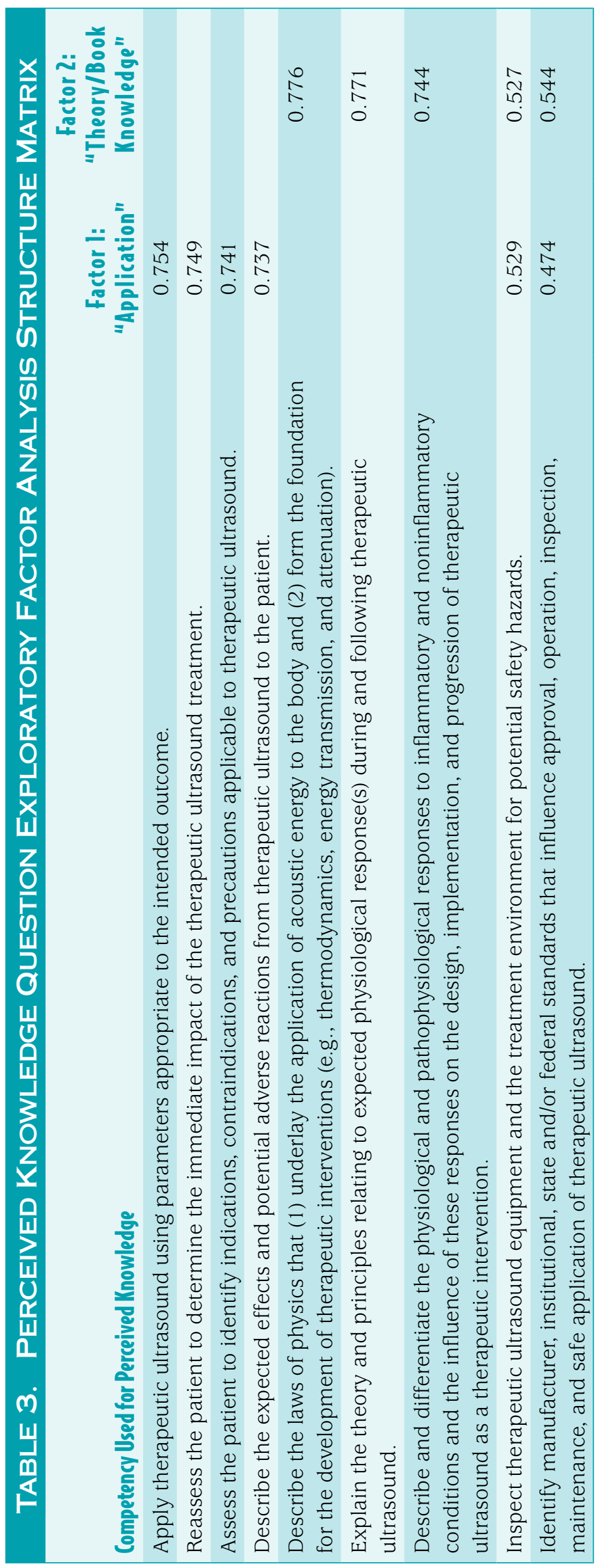




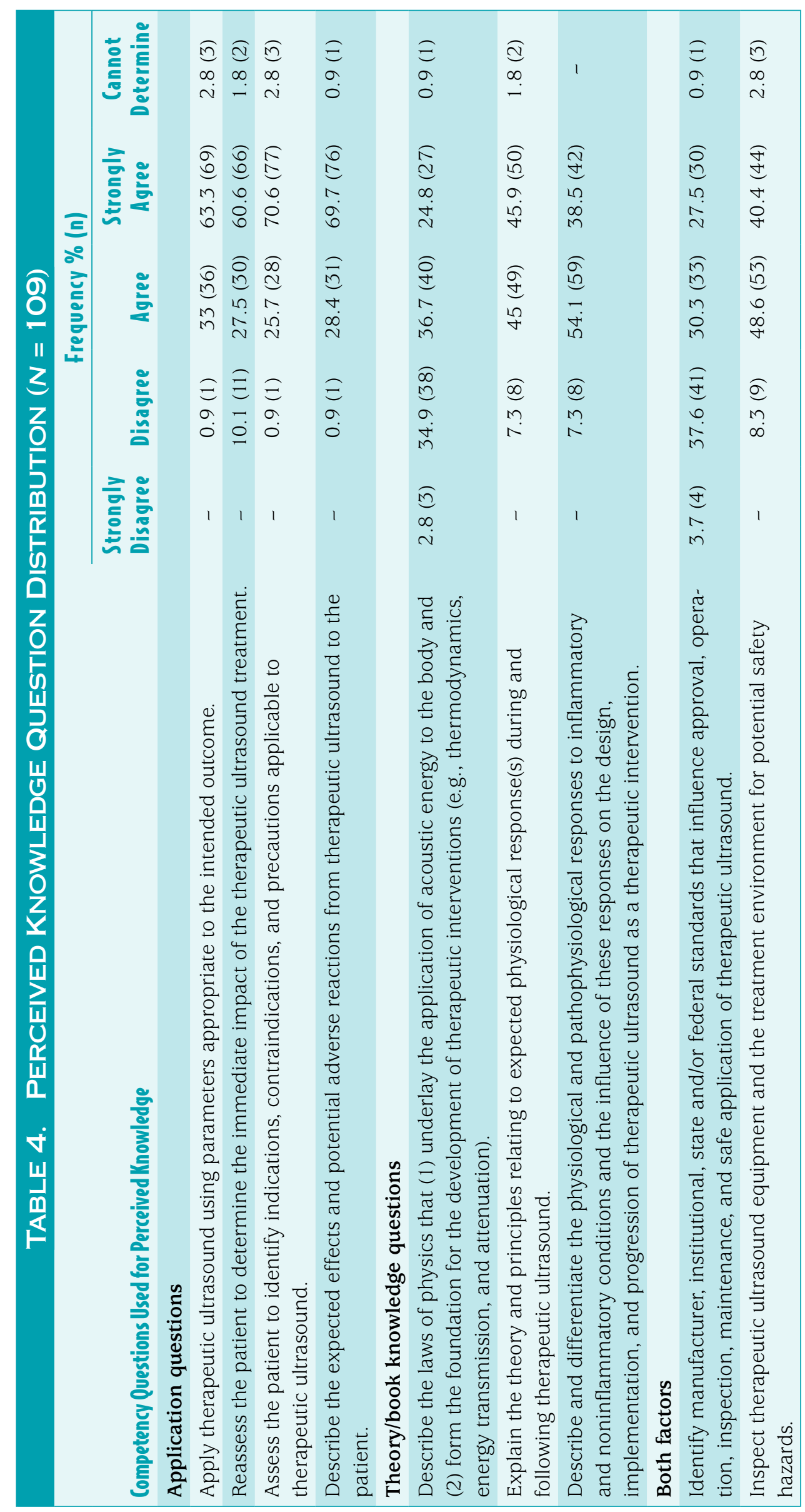




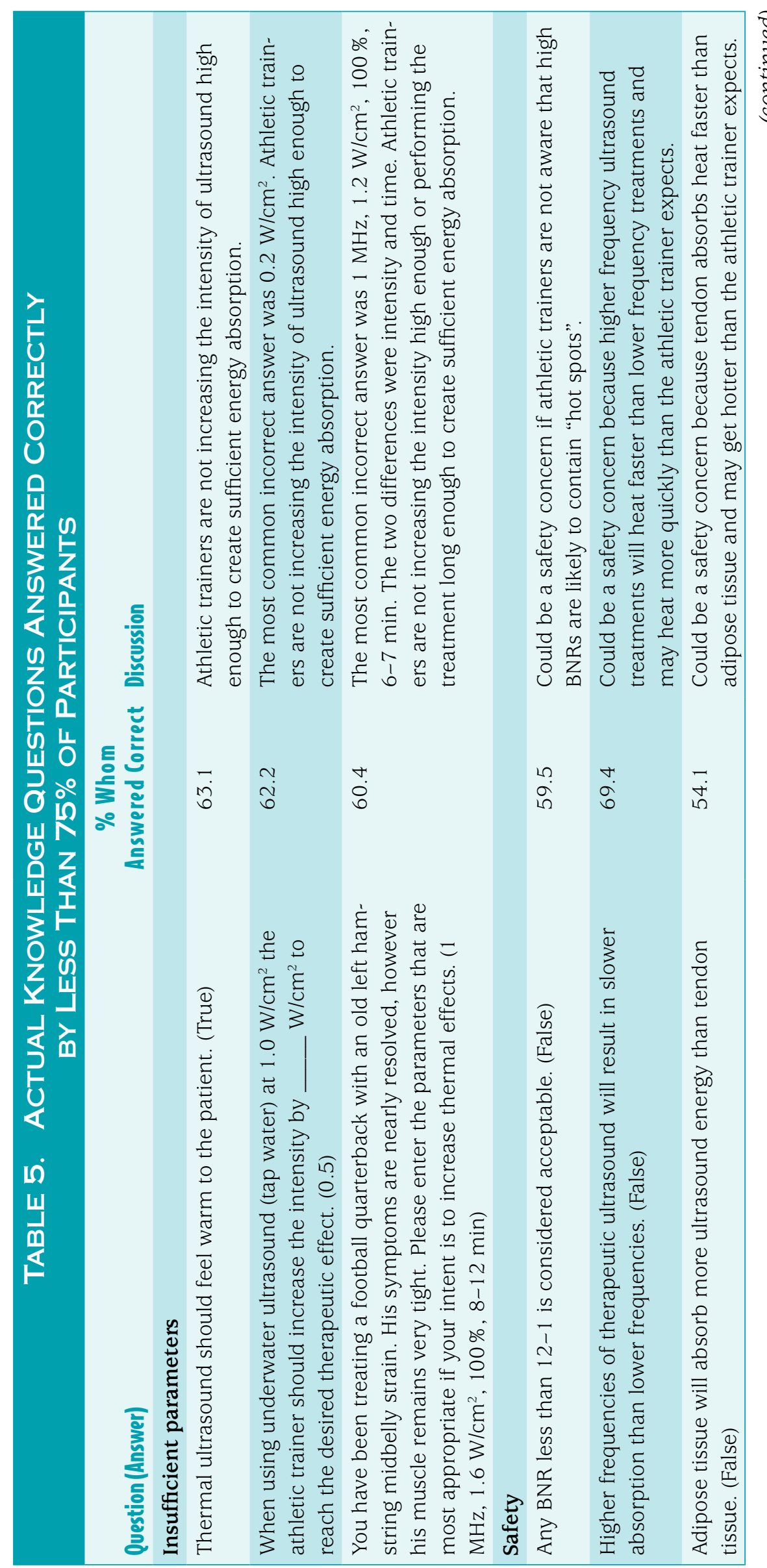




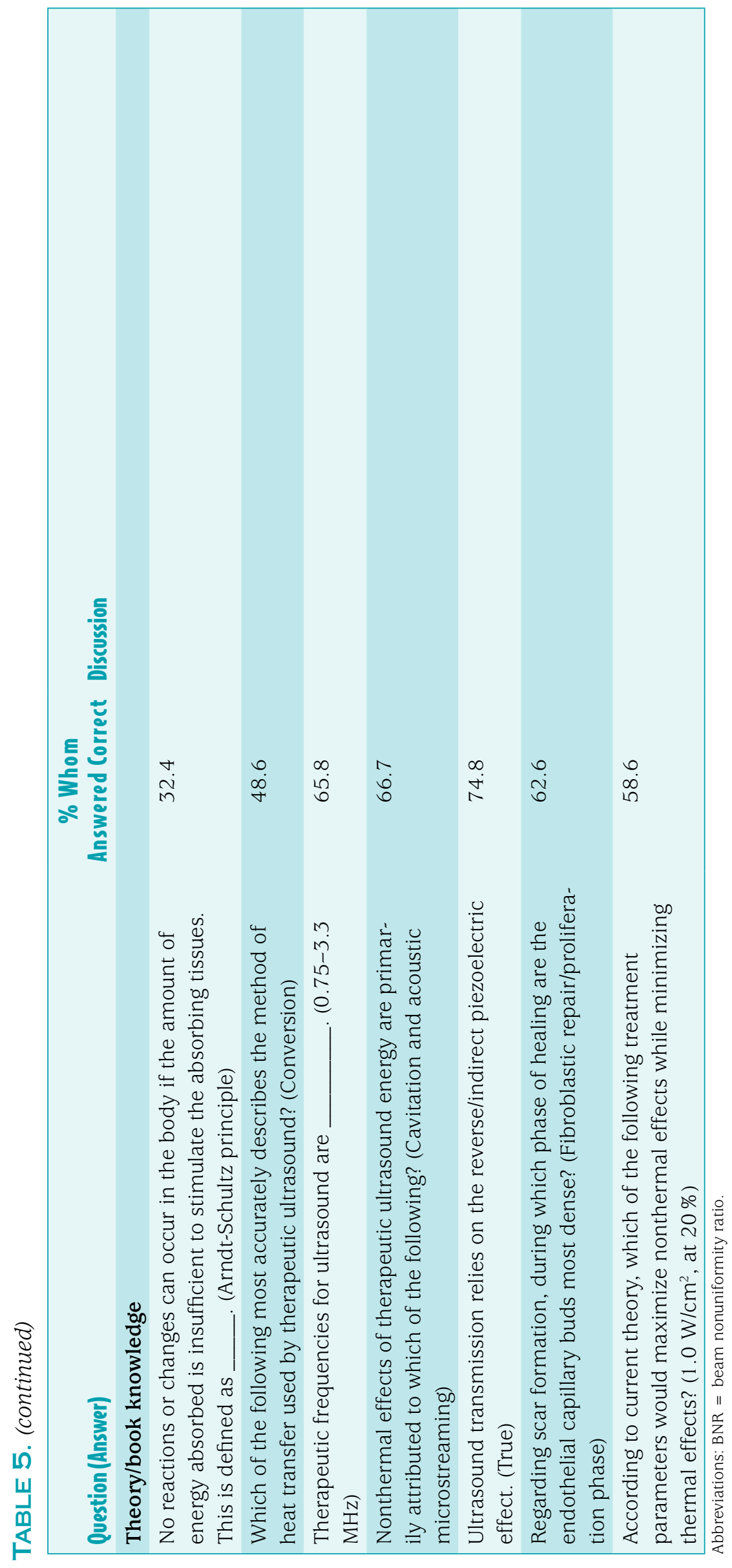


that the respondents in that study felt they had deficiencies in their therapeutic modalities knowledge. The current study indicates that athletic trainers in the collegiate setting do not feel they have deficiencies in their knowledge of therapeutic ultrasound. Overall, participants reported confidence in their understanding of therapeutic ultrasound concepts and in their ability to perform therapeutic ultrasound.

Pitney ${ }^{17}$ evaluated athletic training continuing education within the framework of adult learning theory. He encouraged athletic trainers to identify learning needs through reflection upon any discrepancies between the established competencies and skills and their own current skills. ${ }^{16}$ The BOC recently launched a voluntary Professional Development Needs Analysis (PDNA) tool that aims to assist athletic trainers with the identification of gaps in their knowledge. The PDNA questionnaire asks participants to rank their level of professional development need in each domain by considering their current "level of preparedness" and their need for the knowledge/skill in their own professional practice. ${ }^{17}$ The participants in this study reported confidence in their knowledge of therapeutic ultrasound, however scores on the actual knowledge questions were fairly low. Their perceived knowledge only weakly/moderately correlated to their actual knowledge score. This raises the question about whether the correlation is high enough to make a tool like the PDNA effective.

\section{Actual Knowledge}

Athletic trainers in older age groups and those who had taken more therapeutic modalities courses had higher actual knowledge scores. While it makes sense that more courses would increase an athletic trainer's knowledge of the material, the issue of age is less clear. While experience usually comes with age, younger athletic trainers have likely had more recent exposure to modern concepts of therapeutic ultrasound. It is possible that the older athletic trainers in college/clinical settings have had recent exposure of these modern therapeutic ultrasound concepts through students who have been assigned to them as a part of a professional athletic training program. It is also possible that the older athletic trainers are more likely to be serving in college/academic settings and are perhaps teaching therapeutic modalities courses. Further research would be needed to determine whether age, apart from setting, is correlated to actual knowledge.
An analysis of individual question responses suggests that the common misconceptions that concerned Draper in 1998 are still present. ${ }^{7}$ Thirteen questions were answered correctly by less than $75 \%$ of respondents. These commonly missed questions fell into three categories: insufficient parameters, safety concerns, and theory/book knowledge. An analysis of the incorrect answers in the insufficient parameters category pointed to athletic trainers using intensities that were too low and/or durations that were too short. Draper indicated that athletic trainers were using the same parameters for every injury instead of adjusting intensity, time, and frequency according to the treatment goals. ${ }^{7}$ What is most striking is that $36.9 \%$ of respondents indicated that thermal ultrasound should not feel warm to the patient. This signals that nearly two-fifths of respondents likely are not using intensities high enough to create thermal effects even when thermal effects are desired. This also indicates that athletic training education regarding the therapeutic ultrasound parameters required to meet treatment outcomes is either inadequate or not retained by graduates.

Three questions, identified by the researchers as "safety concerns", suggest that athletic trainers may not be aware of situations when absorption of heat will be either higher or more rapid. Beam nonuniformity ratio (BNR), tissue types that influence absorption, and the effect of frequencies on speed of heating were poorly understood by respondents. However, it is also possible that these practitioners are effective, but specific terminology has been forgotten. These three questions may be best aggregated with the other seven questions that the researchers identified as a loss of "theory/book knowledge" and may or may not raise concerns about actual practice.

\section{Limitations}

One significant limitation of the study was the low response rate, and that only collegiate athletic trainers responded to the research request. This limited the ability to compare the results of this study to athletic trainers working in other settings. This also limits the ability to compare the athletic training results to the results of other professions, such as physical therapy, as there are likely large differences in frequency of use.

An additional limitation is that only specific ultrasound parameters were analyzed. The researchers chose to mainly look at the main parameters of intensity, frequency, and time. The researchers did 
not include a comprehensive assessment of any other parameters such as treatment size or speed of the ultrasound head. These parameters can also influence the amount of thermal effect created during a therapeutic ultrasound treatment.

\section{Conclusions and Implications}

The participants in this study had confidence in their knowledge of therapeutic ultrasound concepts, but scores on the actual knowledge questions were relatively poor. While a self-assessment tool may be helpful for some, this study demonstrates that more research is needed regarding whether athletic trainers have an accurate understanding of their need for continuing education in this area. The use of inadequate intensities and inadequate treatment durations, as outlined by Draper in $1998,{ }^{7}$ were still seen.

\section{References}

1. Lehmann JF, Erickson DJ, Martin GM, Krusen FH. Comparison of ultrasonic and microwave diathermy in the physical treatment of periarthritis of the shoulder: study of the effects of ultrasonic and microwave diathermy when employed in conjunction with massage and exercise. Arch Phys Med Rehabil. 1954;35:627-634. PubMed

2. De Forest RE, Henick JF, Janes JM. Effects of ultrasound on growing bone: an experimental study. Arch Phys Med Rehabil. 1953;34(1):21 31. PubMed

3. Wong RA, Schumann B, Townsend R, Phelps CA. A survey of therapeutic ultrasound use by physical therapists who are orthopaedic certified specialists. Phys Ther. 2007;87(8):986-994. PubMed doi:10.2522/ ptj.20050392

4. Eberman L, Schumacher H, Niemann AJ, Adams HM, Kahanov L. Research evidence for therapeutic ultrasound effectiveness. Int $J$ of Athletic Therapy Train. 2013;18(4):20-22

5. Armijo-Olivo S, Fuentes J, Muir I, Gross DP. Usage patterns and beliefs about therapeutic ultrasound by Canadian physical therapists: an exploratory population-based cross-sectional survey. Physiother Can. 2013;65(3):289-299. PubMed doi:10.3138/ptc.2012-30BC

6. Robertson VJ, Baker KG. A review of therapeutic ultrasound: effectiveness studies. Phys Ther. 2001;81 (7):1339-1350. PubMed

7. Draper DO. Guidelines to enhance therapeutic ultrasound treatment outcomes. Athl Ther Today. 1998;3(6):7-11.

8. Yang $\mathrm{CW}$, Yen ZS, McGowan JE, et al. A systematic review of retention of adult advanced life support knowledge and skills in healthcare providers. Resuscitation. 2012;83(9):1055-1060. PubMed doi:10.1016/j. resuscitation.2012.02.027

9. Seegmiller JG. A model for clinical education in athletic training. Internet J Allied Health Sci Pract. 2003;1(1)1-4.

10. National Athletic Trainers' Association (NATA). Athletic Training Educational Competencies. 5th ed. Dallas, TX: NATA; 2011

11. Certification Maintenance Requirements. Board of Certification website. http://bocatc.org/ats/maintain-certification. Accessed October 1,2014

12. Prentice WE. Therapeutic Modalities for Sports Medicine and Athletic Training. 6th ed. New York, NY: McGraw Hill; 2008:206-255.

13. Starkey C. Therapeutic Modalities. 3rd ed. Philadelphia, PA: FA Davis Co.; 2004:156-173.

14. Knight K, Draper D. Therapeutic Modalities: The Art and Science. Baltimore, MD: Lippincott, Williams \& Wilkins; 2008:254-278.

15. Cuppett MM. Self-perceived continuing education needs of certified athletic trainers. J Athl Train. 2001;36(4):388-395. PubMed

16. Pitney WA. Continuing education in athletic training: An alternative approach based on adult learning theory. J Athl Train. 1998;33:72-76. PubMed

17. Resources CE. Board of Certification website. http://bocatc.org. Accessed March 4, 2014.

Kristen Couper Schellhase has been a lecturer and the program director for the Athletic Training Program at the University of Central Florida since 2004 and the department chair of the Department of Health Professions since 2010.

Jennifer L. Plant has been an instructor and the clinical education coordinator for the Athletic Training Program at the University of Central Florida, Orlando, FL, since 2010.

Carey E. Rothschild has been a lecturer in the Doctor of Physical Therapy Program at the University of Central Florida, Orlando, FL, since 2009.

Lindsey E. Eberman, PhD, ATC, LAT, Indiana State University, is the report editor for this article. 